\title{
Noninvasive Management of Rhesus Alloimmunization
}

\author{
Nirmala Agarwal, Sweta Balani, Subhash Arya, Ratna Dua Puri
}

\begin{abstract}
Rhesus alloimmunization causes fetal hemolysis, anemia and hydrops leading to stillbirth, neonatal morbidity or mortality. We describe successful management of two cases of $\mathrm{Rh}$ alloimmunization with high anti-D titers, by the ultrasound Doppler measurement of their peak systolic velocity in the middle cerebral artery (PSV-MCA) and multiple maternal administrations of intravenous immunoglobulin (IVIg).
\end{abstract}

Keywords: Rhesus alloimmunization, Intravenous immunoglobulin, Middle cerebral artery peak systolic velocity.

How to cite this article: Agarwal N, Balani S, Arya S, Puri RD. Noninvasive Management of Rhesus Alloimmunization. Int J Infertility Fetal Med 2013;4(2):59-61.

Source of support: Nil

Conflict of interest: None

\section{INTRODUCTION}

Maternal rhesus alloimmunization occurs when a rhesusnegative pregnant women develops antibody response to fetal red cell rhesus antigen. These antibodies cross placenta and destroy fetal erythrocytes leading to anemia, hydrops and fetal death. It has been estimated that 35 fetuses out of every 10,000 live births are at a risk of anemia because of maternal rhesus alloimmunization. ${ }^{1}$ Traditionally, such pregnant women were managed by carrying out an amniocentesis, cordocentesis and intrauterine transfusion. Only $10 \%$ of their fetus have severe anemia and require cordocentesis before 34 weeks. ${ }^{2}$ Although cordocentesis allows direct measurement of fetal hemoglobin, it is associated with infection, bleeding, fetal bradycardia, premature rupture of the membranes including a procedurerelated pregnancy loss of $1 \% .{ }^{3}$ Even though amniocentesis is less invasive than cordocentesis, it is reliable only after 27 weeks. $^{4}$

Currently, it is possible to offer an accurate prediction of severity of anemia using ultrasound by measuring peak systolic velocity in the middle cerebral artery (PSV-MCA). ${ }^{5}$ There is a reverse relationship between the fetal hemoglobin concentration and velocity of the cerebral blood flow. To evaluate PSV-MCA, nomograms are made for various gestational age. ${ }^{6}$ Risk of development of anemia has been high in fetus with PSV-MCA of 1.5 times or higher than the median values. On the contrary, fetuses with such value

Date of Received: 22-05-13

Date of Acceptance: 17-06-13

Date of Publication: May 2013 lower than 1.5 MoM have mild anemia or no anemia. To evaluate PSV-MCA, nomograms are made for various gestational age. ${ }^{6}$ Recent studies administering maternal intravenous immunoglobulin (IVIg) have shown some benefit in severe cases. ${ }^{7}$ Studies have been carried out using plasmapheresis with IVIg. The recommended dose has been of $1 \mathrm{gm} / \mathrm{kg}$ which is repeated weekly. ${ }^{9}$

We describe two cases of rhesus alloimmunization that were successfully managed at a private tertiary care hospital by noninvasive technique.

\section{CASE REPORTS}

\section{Case 1}

This patient was 39 years old G5 P4 L1 NND2 SB1 with IVF singleton RH negative 19 weeks pregnancy. Her first pregnancy was uneventful and she had delivered a female baby 19 years earlier. Anti-D was not given in postnatal period. Following this, second and third pregnancy resulted in neonatal death on day 1 due to severe anemia. The fourth pregnancy also ended in a stillbirth at term. In present pregnancy, her antibody titer was 1:256.

The pregnancy was monitored with MCA-PCV according to normogram. ${ }^{5}$ She was given 5 gm of IVIg (IV Nex, Biocon) starting at 19 weeks, IVIg was repeated every 2 weeks. She was followed according to the PSV-MCA value (Table 1). The dose of IVIg was increased to $10 \mathrm{gm}$. Patient declined to receive any IVIg after 26 weeks (financial reason). At 33 weeks, fetal PSV-MCA value showed sudden increase and was plotted in zone b (Graph 1). Repeat Doppler 5 days later, there was further increase in MCAPSV above 1.5 MoM. Emergency cesarean section was done at $34+6$ weeks of pregnancy; a female baby of $2.6 \mathrm{~kg}$ was delivered. Baby's hemoglobin was $5 \mathrm{gm} \%$, with tear drop cell and fragmented RBC. Exchange transfusion was given twice. Newborn was discharged on 8th postnatal day.

\section{Case 2}

This patient was 38-year-old G2P0L0 A1 presented at $8+4$ weeks Rh-negative pregnancy. She was married for 10 years. Her first pregnancy was a quadruplet pregnancy following assisted reproductive technique cycle. She aborted one fetus. The resulting triplet pregnancy was reduced to twin. At 14 weeks, she had a heavy bout of bleeding and aborted both fetuses. Previous report showed that indirect Coombs test was 1:16 at that time and anti-D was not given. 
The present pregnancy was spontaneous singleton pregnancy. Her husband was O positive (homogyous). In this pregnancy, her ICT titer was 1:32. She was given 5 gm of immunoglobulin from 12 week onward and this was repeated every fortnightly. From 18 weeks onward, she was monitored by ultrasound Doppler MCA-PSV (Table 2). At 24 weeks, the PSV-MCA reached zone C of (Mari et al) normogram (Graph 1). IVIg dose was increased to $10 \mathrm{gm}$ fortnightly. In spite of all these measures, the PSV-MCA went into zone B. The dose of IVIg was further increased to 15 gm every 2 weekly. The aim was to avoid PSV-MCA

\begin{tabular}{|c|c|c|c|}
\hline $\begin{array}{l}\text { Period of } \\
\text { gestation }\end{array}$ & $\begin{array}{l}\text { MCA-PSV } \\
(\mathrm{cm} / \mathrm{sec})\end{array}$ & Zone & IVlg dose (gm) \\
\hline 19 weeks & 22 & D & 5 \\
\hline 22 weeks & 26 & $\mathrm{D}$ & 5 \\
\hline 24 weeks & 33.4 & C & 10 \\
\hline 26 weeks & 30 & $\mathrm{D}$ & 10 \\
\hline 28 weeks & 40 & C & - \\
\hline 32 weeks & 46 & C & - \\
\hline 34 weeks & 66 & $\mathrm{~B}$ & - \\
\hline 34 weeks 5 days & 89 & $A$ & - \\
\hline
\end{tabular}

\begin{tabular}{lllc}
$\begin{array}{l}\text { Table 2: The MCA-PSV at different gestational ages and dose of } \\
\text { IVlg given in case 2 }\end{array}$ \\
\hline $\begin{array}{l}\text { Period of } \\
\text { gestation (weeks) }\end{array}$ & $\begin{array}{l}\text { MCA-PSV } \\
(\mathrm{cm} / \mathrm{sec})\end{array}$ & Zone & IVlg dose $(\mathrm{gm})$ \\
\hline 13 & & & 5 \\
17 & & & 5 \\
19 & 27 & $\mathrm{~B}$ & 5 \\
22 & 25.5 & $\mathrm{C}$ & 10 \\
24 & 34 & $\mathrm{C}$ & 10 \\
26 & 28 & $\mathrm{D}$ & 15 \\
28 & 41 & $\mathrm{C}$ & 15 \\
32 & 51 & $\mathrm{~B}$ & 15 \\
33 & 52 & $\mathrm{~B}$ & \\
\hline
\end{tabular}

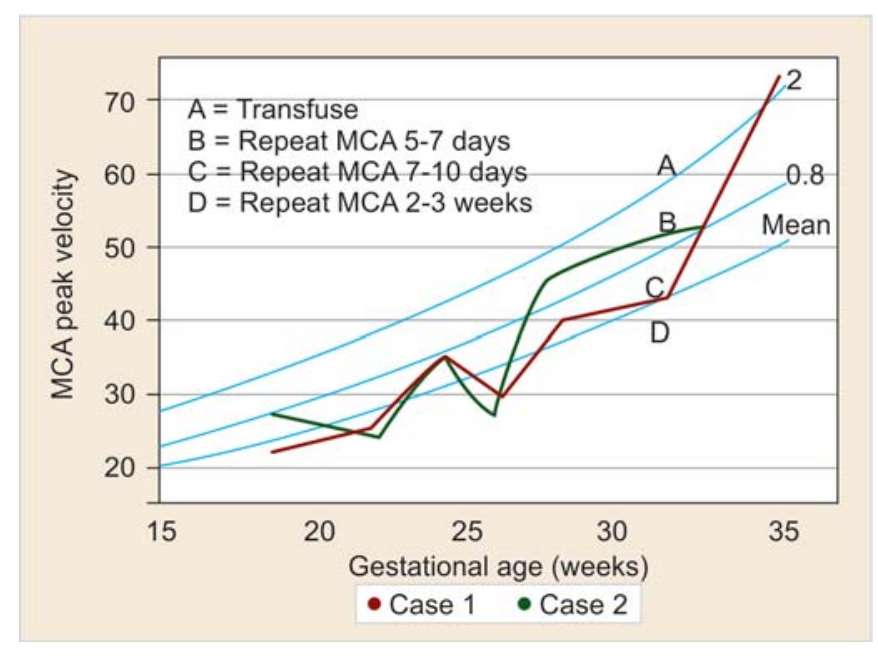

Graph 1: Peak velocity of systolic blood flow in the middle cerebral artery in cases 1 and 2 at various gestational age value to reach zone A where transfusion would have been recommended. Finally at 34 weeks, she was given steroid cover for lung maturation (betamethasone $12 \mathrm{mg}$, two doses at 24 hours interval) and cesarean section was done at 34 weeks. She delivered $2.2 \mathrm{~kg}$ female infant. Baby's hemoglobin was $14 \mathrm{gm} \%$ with a normal peripheral picture and did not require any exchange transfusion and discharged on 3rd day.

\section{DISCUSSION}

The sensitivity of increased PSV-MCA for prediction of moderate to severe anemia was cent percent either in the presence or absence of hydrops with false-positive rate of $12 \% .{ }^{5}$ To the best of our knowledge, the literature on use of IVIg in Rh isoimmunization is scant. Though, anecdotal reports suggest that noninvasive therapy with IVIg may be extremely useful in management of severe Rh isoimmunization. The only concern is the cost of such a therapy which was evident the above case one who had declined IVIg after 26 weeks and was monitored by MCA-PSV. The recommended dose is $1 \mathrm{gm} / \mathrm{kg}$ every week but, in both our cases, we have used lower dose with good outcome. IVIg should not be expected to eliminate the need for intravascular transfusion but can prolong the interval before the first transfusion is necessary. The mechanism of IVIg is not completely known. In all probability, it downregulates maternal antibody response, prevents transport of antibodies across placenta and block destruction of fetal cell by occupying the Fc receptor site. ${ }^{9}$ The typical side effects are urticaria and severe headache. ${ }^{8}$ We encountered no side effect in these two patients. Further research input is warranted to decide the ideal IVIg schedule doses and safety profile, since high dose IVIg is used in neonates to reduce exchange transfusion with hemolytic disease due to rhesus and/or ABO compatibility. This has been and is effective in reducing the duration of phototherapy in the neonates including hospital stay. ${ }^{10}$

The hemoglobin value in the above two neonates were 5 and 14 gm\% respectively. The lower hemoglobin value was most likely due to inadequate dosage of IVIg which had to be discontinued midway. A total of 30 gm was administered in case 1 as compared to 80 gm in case 2 .

\section{CONCLUSION}

The combination of ultrasound Doppler PSV-MCA and IVIg would emerge as an ideal option to manage cases with rhesus alloimmunization. The noninvasive nature will be an asset since it can be carried out without any intervention. Such an approach would more than offset the existing rather prohibitive cost of IVIg. 


\section{ACKNOWLEDGMENT}

We would like to thank Mrs Geeta Rana for her secretarial assistance.

\section{REFERENCES}

1. Public Health Service. Centre for disease control and prevention congenital malformation surveillance. Teratology 1993;48: 545-709.

2. Bowman, John M. Hemolytic disease (erythroblastosis fetalis). In: Creasy, Robert K Resnick, Robert Iams, Jay D, editors. Maternal-fetal medicine. 4th ed. Philadelphia: WB Saunders 1999;736-767.

3. Daffos F, Capella-Pavlovsky M, Forcstier F. Fetal blood sampling during pregnancy with use of a needle guided by ultrasound: a study of 606 consecutive cases. Am J Obstet Gynecol 1985 Nov;153(6):655-660.

4. Nicolaides KH, Rodeck CH, Mibashas RS, Kemp JR. Have Liley chart outlived their usefulness? Am J Obstet Gynecol 1986 Jul; 155(1):90-94.

5. Mari G, Deter RL, Carpanter RL, Rahman F, Zimmerman R, Moisel KJ, Dorman KF, Ludomirsky A, Gonsalex R, Gomez R, et al. Noninvasive diagnosis by Doppler ultrasonography of fetal anemia due to maternal red cell alloimmunization. Collaborative Group for Doppler Assessment to Blood Velocity in Anemic Fetuses. N Eng J Med 2000 Jan;342(1):9-14.

6. Mari G, Andrignolo A, Abuhamad AZ, Pirhonen J, Jones DC, Ludomirsky A, Copel JA. Diagnosis of fetal anemia with Doppler ultrasound in the pregnancy complicated by maternal blood group immunization. Ultrasound Obstet Gynecol 1995 Jun;5(6):400-405.
7. Voto LS, Mather ER, Zapaterio JL, Orti J, Lede RL, Margulies M. High-dose gammaglobulin (IVIG) followed by intrauterine transfusion (IUTs): a new alternative for the treatment of severe fetal hemolytic disease. J Perinat Med 1997;25(1):85-88.

8. Moise KJ Jr. Management of rhesus alloimmunization in pregnancy. Obstet Gynecol 2008 Jul;112(1):164-176.

9. Urbaniak SJ. ADCC (K-cell) lysis of human erythrocyte sensitized with rhesus alloantibody. II. Investigation of mechanism of lysis. Br J Haematol 1979 Jun;42(2):315-328.

10. Gollstein R, Cooke R. Systemic review of intravenous immunoglobulin in hemolytic disease of the neoborn. Arch Dis Child Fetal Neonatal Ed 2003 Jan;88(1):F6-F10.

\section{ABOUT THE AUTHORS}

\section{Nirmala Agarwal (Corresponding Author)}

Senior Consultant and Head, Department of Obstetrics and Gynecology, Sant Parmanand Hospital, New Delhi, India, Phone: 9811888732, e-mail: n.menoky@gmail.com

\section{Sweta Balani}

Consultant, Department of Obstetrics and Gynecology, Sant Parmanand Hospital, New Delhi, India

\section{Subhash Arya}

Laboratory Head, Department of Obstetrics and Gynecology Sant Parmanand Hospital, New Delhi, India

\section{Ratna Dua Puri}

Senior Consultant, Centre of Medical Genetics, Sir Gangaram Hospital New Delhi, India 